\title{
Adición de un probiótico de Lactobacillus plantarum microencapsulado en el alimento para pollos
}

\author{
Addition of a probiotic containing microenscapsulated Lactobacillus plantarum to chicken feed \\ Henry Armando Jurado-Gámez1* orcid.org/0000-0003-2118-7997 \\ Edward Johnny Zambrano-Mora² orcid.org/0000-0002-8443-2243 \\ Alvaro Pazos-Moncayo3 ${ }^{3}$ orcid.org/0000-0001-5603-7898
}

1. Facultad de Ciencias Pecuarias, Departamento de Producción y Procesamiento Animal, Grupo de Investigación PROBIOTEC FORAPIS, Universidad de Nariño. Pasto, Colombia.

2. Facultad de Ciencias Pecuarias, Departamento de Sanidad Animal, Grupo de Investigación PROBIOTEC FORAPIS, Universidad de Nariño. Pasto, Colombia.

3. Facultad de Ciencias Exactas y Naturales, Departamento de Biología, Grupo Salud Pública, Universidad de Nariño. Pasto, Colombia.

Fecha de recepción: Febrero 15 - 2021

Fecha de revisión: Abril 20 - 2021

Fecha de aceptación: Abril 29 - 2021

Jurado-Gámez HA, Zambrano-Mora EJ, Pazos-Moncayo A. Adición de un probiótico de Lactobacillus plantarum microencapsulado en el alimento para pollos. Univ. Salud. 2021;23(2):151-161. DOI: https://doi.org/10.22267/rus.212302.227

\section{Resumen}

Introducción: En producción avícola el uso de antibióticos promotores del crecimiento es limitado, debido al incremento de resistencia bacteriana. Una alternativa evalúa los probióticos microencapsulados y su efecto en la salud intestinal. Objetivo: Determinar el efecto de Lactobacillus plantarum microencapsulado sobre parámetros intestinales e inmunológicos en pollos de engorde. Materiales y métodos: A 240 pollos Ross-308-AP de un día de nacidos se suministró alimento con o sin adición de probiótico bajo el siguiente modelo: sin probiótico- $\left(\mathrm{T}_{0}\right)$, con probiótico comercial- $\left(\mathrm{T}_{1}\right)$, con L. plantarum microencapsulado-( $\left.\mathrm{T}_{2}\right)$ y sin microencapsular-( $\left.\mathrm{T}_{3}\right)$. L. plantarum ATCC-8014 se microencapsuló mediante secado por aspersión, determinando su viabilidad en (\%). Se evaluaron parámetros intestinales, morfo-histopatológicos e inmunológicos por Azul de Alcian, microscopia de barrido e inmunohistoquímica y la abundancia microbial por UFC/mL. Resultados: El microencapsulado confirió una viabilidad in vivo de L. plantarum del $88,1 \%$. El tratamiento $\mathrm{T}_{2}$ mejoró los parámetros inmunológicos y confirió beneficios intestinales con una abundancia de bacterias benéficas (Lactobacillus) de $\left(9,13 \times 10^{5}-\mathrm{UFC} / \mathrm{mL}\right)$, significativamente mayor a la encontrada en los tratamientos $\mathrm{T}_{1}\left(8,91 \times 10^{5}\right)$ y $\mathrm{T}_{3}\left(8,23 \times 10^{5}\right)$ y el control $\mathrm{T}_{0}\left(9,18 \times 10^{4}\right),(p<0,05)$. Conclusiones: La adición de L. plantarum microencapsulado en alimento para pollos mejora parámetros inmunológicos y confiere mayor abundancia de bacterias benéficas presentes en la microbiota intestinal.

Palabras clave: Bacteria; Lactobacillus; microbiota; alimento funcional; probióticos. (Fuente: DeCS, Bireme).

\begin{abstract}
Introduction: Usage of growth-promoting antibiotics in poultry production is limited due to the increase in bacterial resistance. An alternative to assess microencapsulated probiotics and their effect on gut health is presented in this study. Objective: To determine the effect of microencapsulated L. plantarum on intestinal and immunological parameters in broilers. Materials and methods: 240 Ross-308-AP chickens (one day old) were fed with or without the addition of a probiotic, under the following model: without probiotic $\left(\mathrm{T}_{0}\right)$; with commercial probiotic $\left(\mathrm{T}_{1}\right)$; with probiotic containing either microencapsulated $\left(\mathrm{T}_{2}\right)$ or nonmicroencapsulated $\left(\mathrm{T}_{3}\right)$ L. plantarum. ATCC-8014 was microencapsulated by spray drying, assessing its viability in (\%). Alcian blue, scanning microscopy, and immunohistochemistry were used to evaluate intestinal, morpho-histopathological, and immunological parameters. Microbial abundance was quantified by UFC/ml. Results: Microencapsulation of L. plantarum induced an $88.1 \%$ in vivo viability. $\mathrm{T}_{2}$ treatment improved both immunological parameters and the intestinal population of beneficial bacteria (Lactobacillus) $\left(9.13 \times 10^{5} \mathrm{UFC} / \mathrm{ml}\right)$, which was significantly higher than that found in $\mathrm{T}_{1}\left(8.91 \times 10^{5}\right), \mathrm{T}_{3}\left(8.23 \times 10^{5}\right)$, and control $\mathrm{T}_{0}\left(9.18 \times 10^{4}\right)$, $(p<0.05)$. Conclusion: Adding microencapsulated L. plantarum to chicken feed improves immunological parameters and increases the population of beneficial bacteria in the intestinal microbiota.
\end{abstract}

Keywords: Bacteria; Lactobacillus; microbiota; functional food; probiotics. (Source: DeCS, Bireme).

*Autor de correspondencia

Henry Armando Jurado-Gámez

e-mail: henryjugam@gmail.com 


\section{Introducción}

En Colombia y el mundo el pollo se ha posicionado como la principal carne de consumo, lo que estimula a mejorar sus procesos de producción. Sin embargo, la búsqueda de líneas genéticas con crecimiento acelerado por parte de la industria, junto con el manejo de altas densidades animales, trae como consecuencia un aumento de problemas sanitarios, como trazas de antibióticos y detritus metabólicos que llegan al consumidor, contaminación ambiental por residuos del proceso de producción, y aparición de patologías de diferente índole en las aves, como consecuencia del desbalance de la microbiota normal intestinal(1). Ante estos problemas las empresas avícolas utilizan alimentos balanceados que en su composición contienen antibióticos promotores de crecimiento $(\mathrm{APC})^{(2)}$, sin embargo, las dosis administradas de APC son sub-terapéuticas, lo que a mediano plazo presentan dificultades para mantener el estatus sanitario de las producciones pecuarias(3).

Entre los problemas del uso de los APC se encuentra la alteración de la microbiota normal y con ello el metabolismo intestinal de las aves, además de la selección positiva de bacterias resistentes a este tipo

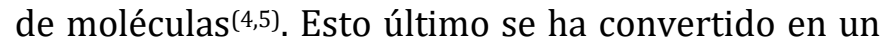
problema de salud pública, dado que la producción de pollo es el primer eslabón de la cadena productiva, derivando en la transmisión de microorganismos y trazas de antibióticos, como también detritus metabólicos que afectan la salud humana del consumidor final(6).

El aumento de resistencia microbiana llevó a los gobiernos a la creación de leyes que regulan y, en muchos casos, prohíben los APC en la alimentación de aves para consumo humano, lo que se convierte en un reto para los actuales sistemas de producción que intentan encontrar un sustituto viable a este tipo de productos(7).

En la actualidad las investigaciones en sanidad pública se encaminan a la búsqueda de microorganismos benéficos (probióticos) como aditivos que reemplacen los APC. Algunos estudios demuestran efectos positivos de las bacterias ácido lácticas y su potencial como agentes moduladores de la microbiota normal del tracto digestivo y su consiguiente salud intestinal, lo que indica que pueden convertirse en una alternativa a los APC y aportar en la solución de problemas prioritarios de salud pública derivados de la ingesta de pollo considerada como la principal carne de consumo humano(8).

Por lo anterior, la presente investigación buscó determinar el efecto de $L$. plantarum microencapsulado sobre parámetros intestinales e inmunológicos en pollos de engorde.

\section{Materiales y métodos}

Localización. La investigación se realizó en las instalaciones de la Clínica Veterinaria Carlos Martínez Hoyos y el laboratorio de investigación PROBIOTECFORAPIS de la Universidad de Nariño. Las instalaciones contaron con calefacción para las aves y el manejo de la humedad ambiental, ajustados según los manuales de procedimientos disponibles en el bioterio que garantizaron la reproducibilidad de los resultados.

Activación y obtención de inóculo. Se utilizó la cepa de referencia L. plantarum ATCC ${ }^{\circledR} 8014$, reconstituida de acuerdo al inserto de la casa comercial. Para la obtención del inóculo se siguieron los protocolos publicados por Jurado et al.(9), donde la cepa fue sembrada en medio De Man, Rogosa y Sharpe, (MRS Oxoid ${ }^{\circledR}$ USA) por un periodo de $24 \mathrm{~h}$, a una temperatura de $37^{\circ} \mathrm{C}$, con una densidad del inóculo de $1,3 \times 10^{13} \mathrm{UFC} / \mathrm{mL}$, obtenida a las $12 \mathrm{~h}$ de incubación, al final de la fase exponencial. Luego de obtener la fase exponencial de crecimiento de L. plantarum, se tomó una muestra mediante asa y con ella se inoculó $40 \mathrm{~mL}$ de caldo MRS comercial De Man, Rogosa y Sharpe, (Oxoid ${ }^{\circledR}$ USA) estéril. Se incubó por $24 \mathrm{~h}$ a $37^{\circ} \mathrm{C}$ en incubadora (Shel Lab ${ }^{\circledR}$ SMI7-Doral, FL 33152USA). Se tomaron $4 \mathrm{~mL}$ del medio incubado para depositarlos en otros $40 \mathrm{~mL}$ de caldo MRS, este se llevó a las mismas condiciones de incubación, calculando al final la densidad celular, en número de bacterias por mL. Cuando se presentó mayor población de la establecida según el Estándar de $M c$ Farland 2, se adicionó caldo MRS estéril, teniendo en cuenta el cálculo matemático de proporcionalidad descrito por Montes et al.(10).

Obtención del microencapsulado. La microencapsulación se realizó según la metodología descrita por Rodríguez et al(11). Se prepararon $400 \mathrm{~mL}$ de inóculo al $15 \% \mathrm{p} / \mathrm{v}$ de $L$. plantarum $(60 \mathrm{~g}$ de Maltodextrina y $60 \mathrm{~g}$ de Inulina en $280 \mathrm{~mL}$ de inóculo a 1,3 x $10^{13} \mathrm{UFC} / \mathrm{mL}$ ) en relación $1: 1 \mathrm{p} / \mathrm{p}$, esta mezcla fue homogenizada y se llevó a equipo de aspersión (Secador Spray Bilon 6.000s, Alemania ${ }^{\circledR}$ ) por 2 h y 30 
min a una temperatura de $170^{\circ} \mathrm{C}$ a la entrada y $67^{\circ} \mathrm{C}$ a la salida. El microencapsulado se almacenó a temperatura ambiente del laboratorio $\left(20^{\circ} \mathrm{C}\right)$ en recipientes de plásticos oscuros, previamente esterilizados.

Evaluación de la viabilidad y eficiencia del microencapsulado. La viabilidad se determinó a los 22 días de la elaboración del microencapsulado. Para este proceso se tomó $1 \mathrm{~g}$ de muestra y se depositó en $9 \mathrm{~mL}$ de agua peptonada tamponada al $0,1 \% \mathrm{p} / \mathrm{v}$, a $\left(20^{\circ} \mathrm{C}\right)$ y un pH de $7,2 \pm 2$; se homogenizó y se dejó reposar por $30 \mathrm{~min}$ a $20^{\circ} \mathrm{C}$. Seguidamente se tomaron $100 \mu \mathrm{L}$ de la mezcla, que fueron sembrados en cajas de petri que contenían agar MRS-Azul de anilina al $0,1 \%$, mediante la técnica de siembra en superficie. Se incubó en aerobiosis (Shel Lab ${ }^{\circledR}$ SMI7-Doral, FL 33152 -USA) por $48 \mathrm{~h}$ a $37^{\circ} \mathrm{C}$, con posterior recuento de colonias en placa por duplicado, expresando los resultados en UFC/g en base seca, según la metodología propuesta por Rodríguez et al(11).

Con los datos obtenidos se calculó el porcentaje de viabilidad de acuerdo con la Ecuación 1.

$$
\% \text { Viabilidad }=\frac{N}{N_{o}} * 100
$$

Donde:

$\mathrm{N}$ : número de células viables por gramo de material encapsulado.

$\mathrm{N}_{\mathrm{o}}$ : número de células viables por gramo de materia seca antes del secado.

La eficiencia se determinó por la metodología de Rodríguez et al.,(11) y Gonzáles et al(12). Para ello se tomaron $2 \mathrm{~g}$ de material encapsulado y se diluyeron en $18 \mathrm{~mL}$ de agua destilada; la mezcla se llevó a centrífuga Harmle Z $326 \mathrm{~K}$ (Nürnberg-Alemania), a $5000 \mathrm{rpm}$ por $15 \mathrm{~min}$ a $20^{\circ} \mathrm{C}$, con el fin de extraer las células libres de L. plantarum. Luego se determinó la concentración bacteriana en el sobrenadante y la eficiencia fue establecida mediante la Ecuación 2.

$$
\% \text { Eficiencia }=\frac{A-B}{A} \times 10 \quad(\text { Ec. } 2)^{(11)}
$$

Donde

A: Concentración bacteriana antes de la microencapsulación.
B: Concentración bacteriana después del microencapsulado.

Características físicas del microencapsulado. Se evaluaron los parámetros humedad, actividad de agua, solubilidad y humectabilidad de acuerdo con Rodríguez et al(11). Para la humedad se tomaron $2 \mathrm{~g}$ de material microencapsulado y se depositaron en el equipo Kern DBS 60-3 (Balingen-Alemania) a una temperatura de $105^{\circ} \mathrm{C}$ con resolución de $0,001 \mathrm{~g}$ y el porcentaje se expresó en base seca. La actividad de agua se determinó en el equipo Termo higrómetro Hygrolab Rotronic (Nürnberg-Alemania) con $2 \mathrm{~g}$ de microencapsulado, el resultado se expresó en porcentaje de base seca. Para determinar la solubilidad se disolvió $1 \mathrm{~g}$ de microencapsulado en $100 \mathrm{~mL}$ de agua destilada, solución que estuvo $5 \mathrm{~min}$ a $30 \pm 2^{\circ} \mathrm{C}$ en incubadora, luego se centrifugó a 3.000 rpm durante $5 \mathrm{~min}$, posteriormente se tomaron 35 $\mathrm{mL}$ de sobrenadante y se transfirieron a una caja de Petri, previamente pesada. La caja se llevó a estufa a $105^{\circ} \mathrm{C}$ por $5 \mathrm{~h}$ hasta obtener un peso constante. Los sólidos obtenidos de la estufa se pesaron (mf) y se determinó el porcentaje de solubilidad con la Ecuación 3.

$$
\text { Solubilidad }=\frac{m i-m f}{m i} * 100 \% \quad(E c .3)^{(11)}
$$

Donde:

mi: $0,25 \mathrm{~g}=\left(1 \mathrm{~g} / 100 \mathrm{~mL}=0,01 \mathrm{~g} / \mathrm{mL}^{*} 25 \mathrm{~mL}\right.$ de líquido sobrenadante).

mf: peso final de la muestra.

La humectabilidad se determinó de acuerdo con Figueroa et al.,(13) y Rodríguez et al.,(11) teniendo en cuenta las condiciones propias del laboratorio. Se utilizó un vaso de precipitado con $100 \mathrm{~mL}$ de agua destilada a $20^{\circ} \mathrm{C}$ y dimensiones de $5 \times 7 \mathrm{~cm}$. Posteriormente, se tomó $1 \mathrm{~g}$ de microencapsulado y se colocó en un porta objetos; este se situó sobre el vaso de precipitado y de manera suave se fue depositando el contenido en agua. La humectabilidad se determinó mediante el tiempo transcurrido del contacto con el agua y la inmersión completa del gramo de muestra.

Morfología y tamaño de microcápsulas. Se tomaron muestras del microencapsulado, que fueron enviadas al Centro de Microscopia y Análisis de la Universidad Nacional de Colombia para realizar fotografías mediante microscopia electrónica de 
barrido y así determinar la forma y el tamaño de la microcápsula. La morfología y tamaño de las microcápsulas fueron determinadas mediante un Microscopio Electrónico de Barrido FEG (Field Emission Gun) QUANTA 650 FEG. Para ello, las muestras se colocaron sobre stabs metálicos con cinta adhesiva de carbón, se recubrieron con oro en un equipo de recubrimiento Quorum 150ES. Las imágenes fueron tomadas con las siguientes características: alto vacío; voltaje de aceleración $10 \mathrm{kV}$; detector para imágenes: Electrones secundarios (SE): everhart thornley detector ETD.

Evaluación in vivo del microencapsulado. Inoculación del alimento. La siembra se realizó previo establecimiento de la carga microbiana encontrada en la fase exponencial de crecimiento, inoculando el alimento balanceado en una relación de $20 \%$ p/v, se homogenizó y se llevó a incubación a $37^{\circ} \mathrm{C}$ durante 24 h. Al final, el alimento se conservó en bolsas plásticas de cierre hermético a temperatura ambiente. En adición, se usó un probiótico comercial como uno de los testigos y para ello se inoculó en el alimento de acuerdo con las instrucciones de la casa comercial.

Procedimiento in vivo-Modelo aviar. Se realizó en 240 pollos machos Ross 308 AP de un día de nacidos, con un peso aproximado de $41 \mathrm{~g}$. Los animales se alojaron en 12 jaulas con capacidad para 20 aves. El manejo fue realizado según las recomendaciones de la casa genética según lo recomendado por Mottet y Tempio(14). Las aves se acostumbraron a la ración durante los 6 primeros días y el experimento se realizó de los 7 a 35 días de edad. Las características del alimento balanceado fueron las siguientes: alimento tipo pollo campesino de una marca comercial reconocida. Este concentrado se caracteriza por no tener aditivos como anticoccidiales ni promotores de crecimiento, con un contenido de proteína cruda del $13 \%$, grasa del $2 \%$, una humedad máxima del $13 \%$, fibra del $13 \%$ y un contenido de ceniza máximo del $10 \%$. Y alimento balanceado con antibióticos y anticoccidiales con un contenido de proteína cruda del $12 \%$, grasa del $2,5 \%$, una humedad máxima del $12 \%$, fibra del $8 \%$ y un contenido de ceniza máximo del 8\%. La alimentación de las aves se realizó en dos tiempos (mañana y tarde). En la alimentación de la mañana se suministró el probiótico en sus dos formas (microencapsulado y sin microencapsular, es decir, por aspersión), y en la tarde sólo la ración de concentrado respectivo sin microorganismos manejando ad libitum, para así permitir la expresión libre del consumo y de la ganancia de peso en los diferentes grupos.

Los animales se distribuyeron de forma aleatoria en cuatro tratamientos. El primero se alimentó con dieta comercial sin aditivos, línea campesina sin aditivos como anticoccidiales ni promotores de crecimiento $\left(\mathrm{T}_{0}\right)$; el segundo, dieta comercial con probiótico comercial $\left(\mathrm{T}_{1}\right)$; el tercero, dieta comercial con inclusión de L. plantarum microencapsulado $\left(\mathrm{T}_{2}\right)$; y el cuarto, dieta comercial con inclusión de L. plantarum $\sin$ microencapsular $\left(\mathrm{T}_{3}\right)$. El alimento y agua fueron suministrados de forma ad libitum.

Morfología gastrointestinal. Al terminar el periodo de estudio (a los 35 días de edad del animal), se sacrificaron 10 aves por grupo, las cuales fueron seleccionadas de manera aleatoria. Se efectuó la disección y extracción del intestino delgado, se identificó la sección anatómica para localizar los órganos al momento de la evaluación microscópica siguiendo la técnica de necropsia aviar, estandarizada por Senne et al.(15). Se tomaron 6 muestras por tratamiento, de las cuales dos se utilizaron para marcadores inmunológicos; dos para microscopia electrónica; y dos para histología. Las muestras se almacenaron por $24 \mathrm{~h}$ en recipientes plásticos rotulados que contenían formol tamponado al 10\%. Luego de la fijación el patólogo veterinario realizó cortes del tejido seleccionado y obtenido de las necropsias (6 segmentos, intestino delgado), ubicaron en cassettes para inclusión de tejidos debidamente rotulados y se almacenaron en recipientes con formol buferado al $10 \%$. Seguidamente se procesaron mediante la técnica de inclusión en parafina y coloración de Hematoxilina y Eosina $(\mathrm{H} / \mathrm{E})^{(16)}$.

Tinciones diferenciales. La producción de mucina intestinal se determinó mediante tinción de las células caliciformes con Azul de Alcian. Las muestras se procesaron por los métodos de rutina para microscopia de luz (Nikon, Serie ECLIPSE 80i, Japón) y las secciones histológicas (3-4 $\mu \mathrm{m}$ de grosor) se colorearon con Azul de Alcian ajustada a un pH de 3,0. La cuantificación de células productoras de IgA se realizó mediante la técnica de inmunohistoquímica(16), determinando el número de células en 2,37 $\mathrm{mm}^{2}$ de GALTT. Los tejidos se observaron en objetivo 40X con microscopio Nikon Eclipse 80i, camera infinity y el software Image Pro Plus 5.0 software (Media Cybernetics, Silver Spring, MD, USA). 
Respuesta post vacunal. Se evaluaron las vacunas de Gumboro, Newcastle y Bronquitis, que se administraron a los pollos el día 1 de vida. Al final del periodo de evaluación ( 35 d) se tomaron muestras de sangre de la vena ala ( 2 a $3 \mathrm{~mL}$ por ave) tomadas con aguja calibre 20 a 22 de $1 / 2$ a 1 pulgada, usando jeringas desechables de 3 a 5 c.c. Durante el sacrificio, se separó el suero, se congeló y se envió las muestras al laboratorio Pronavícola. Los sueros se evaluaron por la técnica de Inmunohemaglutinación (New Castle, bronquitis) mediante el lavado de glóbulos rojos del pollo, para esto se colocaron de 3 a $5 \mathrm{~mL}$ de sangre con solución de Alsever en un volumen 1:1 en un tubo de ensayo de $10 \mathrm{~mL}$, completándose con PBS (buffer fosfato salino), luego se centrifugó (10 min/1.800 rpm) en la centrífuga universal marca Hermle, serie Z $216 \mathrm{M}$, marca alemana y se extrajo el sobrenadante y Elisa (Gumboro) que se caracteriza por ser un ensayo inmunoenzimático utilizado comúnmente en la detección de un Antígeno (Ag) inmovilizado sobre una fase sólida, empleando Anticuerpos (Ac); esto quiere decir que se basa en el reconocimiento específico de antígeno-anticuerpo conjugado a una enzima, cuyo producto de reacción da lugar a un complejo coloreado llamado cromóforo que se cuantifica en un lector de ELISA mediante un método científico llamado espectrofotometría, utilizado para medir la cantidad de luz que absorbe una sustancia química cuando un haz de luz pasa a través de la muestra, usando un equipo de origen chino, marca BIOBASE, serie ELISA3. De esta manera, se determina la duración de la vacuna durante el periodo productivo, es decir, la persistencia de los anticuerpos en los diferentes grupos de estudio.

Exclusión competitiva. Se determinó el número de microorganismos en los medios Agar MRS para Bacterias Ácido Lácticas (BAL) y petrifilm (3M, Minessota, EEUU) para Escherichia coli y coliformes. El conteo se realizó de acuerdo con la técnica de diluciones seriadas y siembra en placa(17). De esta manera, se tomaron cuatro pollos de un día del mismo lote del grupo recibido para la investigación, con el fin de verificar si el pollo trae o no microbiota en su sistema digestivo. Al final del ensayo se realizó este mismo procedimiento con 2 animales por réplica, para verificar y cuantificar la implantación del lactobacilo y la presencia y cantidad (UFC/mL) de $E$. coli y coliformes.

Análisis estadístico. Las variables se evaluaron mediante técnicas descriptivas $y$ un diseño completamente aleatorizado con cuatro tratamientos, tres réplicas por tratamiento y 20 aves por réplica. El análisis de la información se realizó en el paquete estadístico SPSS (Wagner)(18).

Consideraciones éticas. Para realizar el presente estudio, se tuvo en cuenta los principios de ética biomédica descritos por Beauchamp(19), a saber: respeto de la autonomía, beneficencia, no maleficencia y justicia. Para la manipulación de los animales del estudio, se tuvo en cuenta los protocolos establecidos para la cría industrial de aves de engorde, proporcionándoles el ambiente y la alimentación necesaria para poder observar su rendimiento zootécnico. El probiótico se consideró como aditivo para su incorporación en el alimento con el mínimo de efecto perjudicial para el animal. También se consideró la "Guía para el cuidado y uso de animales de laboratorio (2011)" y la normatividad nacional vigente: Resolución 008430 de 1993 del Ministerio de Salud Colombiano, y la Ley 84 de 1989 que contempla los lineamientos para el uso de animales vivos en experimentos e investigación, así como el sacrificio de animales y la crueldad para con los animales. El sacrificio de los animales se realizó mediante el método establecido para el beneficio de aves, por aturdimiento y dislocamiento cervical, proceso que no genera sufrimiento en las aves.

\section{Resultados}

Los parámetros para la evaluación del proceso de microencapsulado de $L$. plantarum se pueden observar en la Tabla 1 . Se encontró una viabilidad del $88,1 \%$, una eficiencia alta $(92,9 \%)$ y una excelente solubilidad (98,3\%).

Tabla 1. Evaluación de la efectividad de la microencapsulación de L. plantarum

\begin{tabular}{lr}
\hline Factor & \multicolumn{1}{c}{ Valor } \\
\hline Viabilidad (22 d) & $88,1 \%$ \\
Eficiencia (22 d) & $92,9 \%$ \\
Humedad relativa & $5,26 \%$ \\
Actividad de agua & 0,33 \\
Humectabilidad & $1 \mathrm{~h}, 28 \mathrm{~min}$ \\
Solubilidad & $98,3 \%$ \\
\hline
\end{tabular}

Los resultados para el tamaño y forma del microencapsulado se pueden observar en la Figura 2. Se obtuvo tamaños de microcápsulas entre los 15,18 a $35,68 \mu \mathrm{m}$ con un promedio de 26 y coeficiente de variación del $26 \%$. La forma del microencapsulado 
fue esférica. La humedad relativa encontrada 5,26\%, que influye en el tamaño del microencapsulado y evita la contaminación bacteriana y micóticas. Por tanto una humedad relativa junto con la actividad del agua $(0,33)$, bajas, mejora la supervivencia de la bacteria microencapsulada. Los resultados microbiológicos y tinciones especiales (inmunohistoquímica y Azul de Alcian) se pueden observar en la Tabla 2.

Se observó valores significativamente más altos del género Lactobacillus en el tratamiento $\mathrm{T}_{2}$, comparado con los tratamientos $\mathrm{T}_{3}$ y el control $\mathrm{T}_{0}$, sin ser significativo el conteo de (UFC/mL) frente al tratamiento que incluyo probiótico en la dieta comercial $\left(\mathrm{T}_{1}\right)$. No se detectó presencia de E. coli en ninguno de los tratamientos. Se encontró mayor número de coliformes totales en el tratamiento To, sin embargo la mayor abundancia de Lactobacillus en el tratamiento $\mathrm{T}_{2}$ confirió beneficios intestinales que se pueden evidenciar en una proporción significativamente mayor de Lactobacillus/Coliformes $(8225,23)$ para $\mathrm{T}_{2}$ que la encontrada en los tratamientos $\mathrm{T}_{3}(1679,59) ; \mathrm{T}_{1}$ $(17,86)$ y el control $\mathrm{T}_{0}(96,03)$ (Tabla 2$)$.

Se encontró que los conteos de células por inmunohistoquímica como marcador de producción de IgA secretora para el tratamiento $\mathrm{T}_{2}$, dieta con $L$. plantarum microencapsulado, fue mayor al encontrado en los tratamientos $\mathrm{T}_{3} ; \mathrm{T}_{1} \mathrm{y}$ el control $\mathrm{T}_{0}$, sin ser estas diferencias significativas. Para el contéo de células por Azul de Alcian, se observó un conteo de caliciformes como marcador de la producción de mucinas, significativamente más alto en el tratamiento $\mathrm{T}_{0}$, comparado con los tratamientos: dieta comercial con probiótico comercial $\left(\mathrm{T}_{1}\right)$, dieta comercial con inclusión de $L$. plantarum microencapsulado $\left(\mathrm{T}_{2}\right)$ y dieta comercial con inclusión de L. plantarum sin microencapsular $\left(\mathrm{T}_{3}\right)$, $(p<0,05)$, Tabla 2 .

Estos resultados evidencian procesos inflamatorios en el grupo de tratamiento, dieta comercial sin aditivos $\left(\mathrm{T}_{0}\right)$, en tanto los hallazgos observados en histología de su tejido intestinal como infiltración linfocitaria, enteritis necrótica, hiperplasia de células caliciformes y fusión de vellosidades, lo confirman, Figura 1, D, E y C. Estas observaciones indican procesos inflamatorios acompañados de hiper producción de moco o mucinas que en su conjunto describen alteraciones patológicas en el tratamiento $\mathrm{T}_{0}$, Figura 1, D, E y C; Tabla 2.

Para las enfermedades de NewCastle, Gumboro y Bronquitis los títulos de anticuerpos IgG, pos vacunación fueron significativamente mayores para los tratamientos con L. plantarum $\left(\mathrm{T}_{2}\right.$ y $\mathrm{T}_{3}$ ) (Figura $1 \mathrm{~A}$, $1 \mathrm{~B}$ y $1 \mathrm{C}$ respectivamente).

En la figura 2A, 2B y 2C se observan los hallazgos histopatológicos encontrados mediante las tinciones. Se identificó lesiones entero necróticas (EN) en todos los tratamientos, sin embargo, el tratamiento $\mathrm{T}_{3}(L$. plantarum sin microencapsular) presentó estas lesiones en el $100 \%$ de las muestras. La atrofia de vellosidades (AV) no se presentó en el control $\left(\mathrm{T}_{0}\right)$, pero sí en los demás tratamientos, con un valor muy elevado en el tratamiento $\mathrm{T}_{3}$. La fusión de vellosidades (FV) y el conteo de caliciformes fueron mayores en el tratamiento $\mathrm{T}_{3}$. Las lesiones más representativas están en el tejido de las aves que fueron alimentadas con L. plantarum, lo que indica que se deben completar los estudios en la cantidad suministrada y el ajuste del inóculo agregado en el alimento de los pollos.

Tabla 2. Parámetros microbiológicos e histoquímicos en pollos de engorde Ross, según tratamientos

\begin{tabular}{|c|c|c|c|c|}
\hline \multicolumn{5}{|c|}{ Parámetros microbiológicos } \\
\hline Variable & $\mathbf{T}_{\mathbf{0}}$ & $\mathrm{T}_{1}$ & $\mathbf{T}_{2}$ & $\mathbf{T}_{3}$ \\
\hline Lactobacillus (UFC/mL) & $9,18 \times 10^{4} \mathrm{c}$ & $8,91 \times 10^{5} \mathrm{~b}$ & $9,13 \times 10^{5} \mathrm{a}$ & $8,23 \times 10^{5} b$ \\
\hline E. coli $(\mathrm{UFC} / \mathrm{mL})$ & 0 & 0 & 0 & 0 \\
\hline Coliformes totales (UFC/mL) & $9,56 \times 10^{2} \mathrm{~b}$ & $4,99 \times 10^{4} \mathrm{C}$ & $1,11 \times 10^{2} \mathrm{a}$ & $4,9 \times 10^{2} \mathrm{a}$ \\
\hline Proporción Lactobacillus/Coliformes & 96,03 & 17,86 & 8225,23 & 1679,59 \\
\hline \multicolumn{5}{|c|}{ Conteo de células según tratamientos } \\
\hline Inmunohistoquímica (células marcadas para IgA) & $375 a$ & $370 \mathrm{a}$ & $390 \mathrm{a}$ & $383 a$ \\
\hline Caliciformes Azul de Alcian (células teñidas) & $1669 \mathrm{a}$ & $1110 \mathrm{~b}$ & $1461 \mathrm{c}$ & $1372 \mathrm{c}$ \\
\hline
\end{tabular}



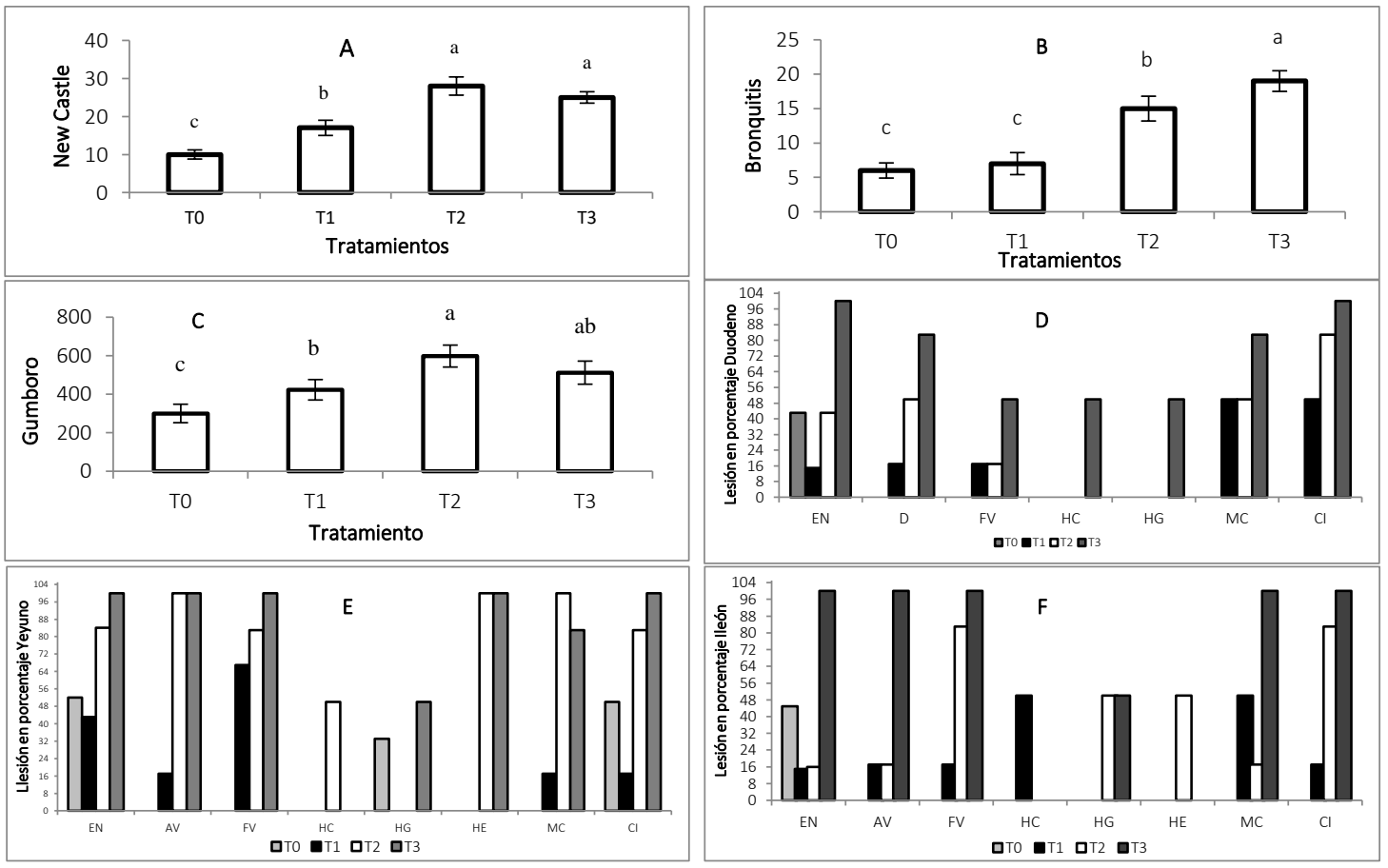

Figura 1. Títulos de anticuerpos para las vacunas. New Castle (A), Bronquitis (B) y Gumboro (C). $\mathbf{T}_{\mathbf{0}}$ : dieta comercial sin aditivos, $\mathbf{T}_{1}$ : dieta comercial con probiótico comercial, $\mathbf{T}_{2}$ : dieta comercial con inclusión de lactobacillus plantarum microencapsulado, $\mathbf{T}_{3}$ : dieta comercial con inclusión de L. plantarum sin microencapsular. Letras diferentes en la parte superior de las gráficas de cajas y bigotes indican diferencias significativas en el título de anticuerpos para las vacunas respectivas. Dimensión de lesiones intestinales evaluadas por histopatología. Lesiones en duodeno (D), Lesiones en yeyuno (E) y Lesiones en íleon (F). EN: enteritis necrótica, AV: atrofia de vellosidades, FV: fusión de vellosidades, HC: hiperplasia de caliciformes, HG: hiperplasia de glándulas, HE: hiperplasia de epitelio, MC: muerte celular, CI: cambios inflamatorios.
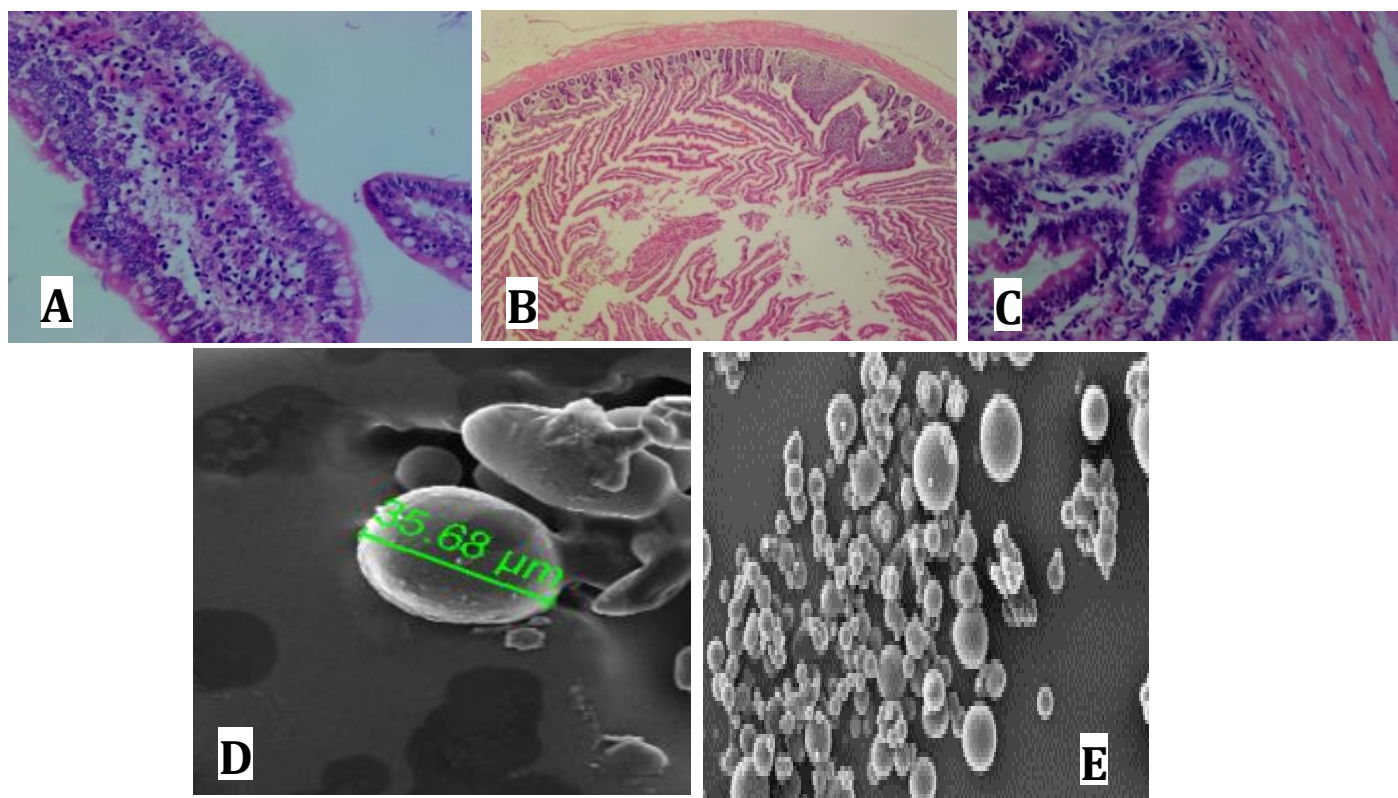

Figura 2. Histología del tratamiento con L. plantarum microencapsulado, según lesiones de intestino de pollos y microfotográfia del encapsulado. A. Corte histológico de microvellosidades con implantación de lactobacilos. B. Atrofia severa y fusión de microvellosidades. C. Infiltración linfoplasmositaria en la lámina propia. D. Dimensiones de la microcápsula, y E Microencapsulado. Microscopio Electrónico de Barrido, Hitachi High-Tech Europe GmbH. 


\section{Discusión}

La viabilidad encontrada $(83,1 \%)$ indica que es posible recuperar in vivo un alto número de células o colonias en medio de cultivo de la especie $L$. plantarum, luego del suministro del alimento al grupo de tratamiento de pollos suplementados con dieta comercial y adición de L. plantarum microencapsulado, en concordancia con lo encontrado en un estudio similar reportado por Sinsajoa et al.,(20) quienes obtuvieron un $(83,3 \%)$ de viabilidad. Estos resultados permiten confirmar que la conservación de la cepa es efectiva mediante la técnica de microencapsulación por secado por aspersión. La humedad relativa encontrada 5,26\%, influye en el tamaño del microencapsulado y evita la contaminación bacteriana y micótica. Por tanto una humedad relativa junto con la actividad del agua $(0,33)$, bajas, mejora la supervivencia de la bacteria microencapsulada. Sin embargo, los resultados de la eficiencia fueron limitados, esto puede ser consecuencia posiblemente del proceso de elaboración del microencapsulado. De acuerdo con Ramos et al.,(21) esta variable está afectada por factores como la temperatura, humedad y la presión, lo que puede indicar problemas en el proceso de elaboración del microencapsulado.

En las variables físicas del microencapsulado, se encontró que los valores de actividad de agua (aw), humectabilidad y solubilidad están entre lo observado por diferentes reportes(22-24), que muestra lo adecuado de la técnica para estos parámetros. Sin embargo, la humedad es mayor a lo sugerido por Samedi y Charles ${ }^{(25)}$, para secado por aspersión $[3,5$ a $4,0 \%$ ), sin afectar valores esperados de variables de interés como la viabilidad. La forma y tamaño del microencapsulado tuvieron un tamaño adecuado, dado que Rodríguez y Jiménez(26), señalan que el tamaño debe estar entre 6,4 y $120 \mu \mathrm{m}$ para mantener la viabilidad y conservación de la cepa. Esta investigación encontró valores significativamente más altos (UFC/mL) del género Lactobacillus en el tracto intestinal de los pollos tratados con dieta comercial con inclusión de $L$. plantarum microencapsulado, traduciéndose en una mayor abundancia de estos microorganismos benéficos, comparado con los tratamientos, dieta comercial con inclusión de L. plantarum sin microencapsular, dieta comercial con probiótico comercial, y dieta comercial sin aditivos.
Un hallazgo que se deriva de la discusión anterior relacionado a que la mayor abundancia de Lactobacillus se encontró en el tratamiento con adición en el alimento para pollos Ros de L. plantarum microencapsulado, se traduce en beneficios intestinales que se pueden evidenciar en una proporción significativamente mayor de Lactobacillus/Coliformes en este grupo, que la encontrada en los tratamientos dieta comercial con inclusión de L. plantarum sin microencapsular, dieta comercial con probiótico comercial, y dieta comercial sin aditivos (Tabla 2). Hallazgo que posibilita la sustitución de los APC por L. plantarum microencapsulado adicionado a la dieta básica de los pollos de engorde y resolver problemas de salud pública asociados a la alteración de la microbiota normal intestinal humana concomitante con la disminución de la selección positiva de bacterias resistentes a los $\operatorname{APC}(4,5)$.

Esto último se ha convertido en un problema de salud pública, dado que la producción de pollo es el primer eslabón de la cadena productiva, derivando en la transmisión de microorganismos y trazas de antibióticos como también detritus metabólicos que afectan la salud humana del consumidor final(6).

Algunos estudios demuestran efectos positivos de las bacterias ácido lácticas y su potencial como agentes moduladores de la microbiota normal del tracto digestivo y su consiguiente salud intestinal, lo que indica que pueden convertirse en una alternativa a los APC y aportar en la solución de problemas prioritarios de salud pública derivados de la ingesta de pollo considerada como la principal carne de consumo humano(8).

Se encontró que los conteos de células por inmunohistoquímica como marcador de producción de IgA secretora para el tratamiento $\mathrm{T}_{2}$, dieta con $L$. plantarum microencapsulado, fue mayor al encontrado en los tratamientos dieta comercial con inclusión de L. plantarum sin microencapsular, dieta comercial con probiótico comercial, y dieta comercial sin aditivos. Para el conteo de células por Azul de Alcian, se observó un conteo de caliciformes como marcador de la producción de mucinas, significativamente más alto en el tratamiento control, dieta comercial sin aditivos comparado con los tratamientos: dieta comercial con probiótico comercial $\left(\mathrm{T}_{1}\right)$, dieta comercial con inclusión de $L$. plantarum microencapsulado $\left(\mathrm{T}_{2}\right)$ y dieta comercial con inclusión de L. plantarum sin microencapsular 
(Tabla 2). Estos resultados evidencian procesos inflamatorios en el grupo de tratamiento dieta comercial sin aditivos $\left(\mathrm{T}_{0}\right)$, en tanto los hallazgos observados en histología de su tejido intestinal como infiltración linfocitaria, enteritis necrótica, hiperplasia de células caliciformes y fusión de vellosidades, lo confirman, Figura 1, D, E y C. Estas observaciones indican procesos inflamatorios acompañados de hiper producción de moco o mucinas que en su conjunto describen alteraciones patológicas en el tratamiento, dieta comercial sin aditivos

Algunas limitaciones del presente estudio se refieren a alteraciones histopatológicas en los tratamientos con suministro de L. plantarum. Es posible que la posología y la densidad celular de los inóculos de la bacteria láctica podrían estar asociadas a las lesiones en el tracto gastrointestinal de las aves. En la literatura se ha encontrado que los probióticos en condiciones inadecuadas pueden tener efectos indeseables en el huésped, como la presencia de alteraciones en la mucosa gástrica por un elevado crecimiento bacteriano(27).

La enteritis necrótica en pollos se relaciona con infección por Clostridium perfringens(28-32). Este tipo de lesión se encontró con mayor porcentaje en el $\mathrm{T}_{3}$, al igual que muerte celular y cambios inflamatorios. Por otra parte, la enteritis necrótica se ha correlacionado con la presencia de otras enfermedades infecciosas, tal como coccidiosis $\mathrm{y}$ enfermedad de la bursa ${ }^{(29,30)}$. Esto es importante para las aves porque representa un mayor equilibrio en la microbiota gastrointestinal como consecuencia del antagonismo con microorganismos patógenos(31).

Los resultados indican un buen estatus sanitario de los animales, pudiéndose establecer una correlación con el mayor número de lactobacilos en algunos tratamientos, en especial dieta comercial con adición de L. plantarum microencapsulado y en la abundancia relativa de bacterias benéficas en la microbiota gástrica de este grupo de aves. Por otra parte, la variable coliformes totales tuvo mayor porcentaje en el tratamiento $\mathrm{T}_{1}$ (probiótico comercial), lo que indica que el contenido nutricional del producto comercial permite un incremento de la población microbiana de los animales(32).

Se evidenció en los tratamientos con las cepas lácticas $\mathrm{T}_{2} \mathrm{y} \mathrm{T}_{3}$, un estímulo sobre el sistema inmune, que posiblemente podría mejorar la productividad del pollo de engorde. Al respecto, Rioux et al.(33), hallaron un aumento de la seroconversión ante el antígeno postvacunal en sangre con la adición de L casei en la dieta de pollos de engorde, lo que concuerda con los hallazgos de esta investigación. Esto demuestra la efectividad de los tratamientos $\mathrm{T}_{2}$ y $\mathrm{T}_{3}$, L. plantarum microencapsulado y sin microencapsular para inducir y mantener por un mayor tiempo altos títulos de anticuerpos (IgA secretora) pos vacunales en la vida productiva de las aves.

\section{Conclusiones}

La técnica de secado por aspersión es eficiente en la microencapsulación de la bacteria láctica. El suministro de L. plantarum microencapsulado en el alimento para pollos mejora parámetros inmunológicos y confiere mayor abundancia de bacterias benéficas presentes en la microbiota intestinal. L. plantarum microencapsulado induce y mantiene altos títulos de anticuerpos post vacunales en la vida productiva de las aves.

Se necesita continuar con la investigación en lo referente a dosis, vía de administración y frecuencia de suministro del probiótico, ya que se observó lesiones gastrointestinales posiblemente por un exceso de microorganismos en la alimentación.

\section{Referencias}

1. Ángel-Isaza J, Mesa-Salgado N, Narváez-Solarte W. Organic acids, an alternative in poultry nutrition: a review. Rev. CES Med. Zootec. 2019;14(2):45-58. Disponible en: http://www.scielo.org.co/pdf/cmvz/v14n2/1900-9607cmvz-14-02-45.pdf

2. Kim W, Lillehoj H. Immunity, immunomodulation, and antibiotic alternatives to maximize the genetic potential of poultry for growth and disease response. Animal Feed Science and Technology. 2019;250:41-50. Disponible en: https://doi.org/10.1016/j.anifeedsci.2018.09.016

3. Oyedeji A, Msagati T, Williams A, Benson N. Determination of antibiotic residues in frozen poultry by a solid-phase dispersion method using liquid chromatography-triple quadrupole mass spectrometry. Toxrepor. 2019;6:951-6. doi: 10.1016/j.toxrep.2019.09.005

4. Wu Z. Antimicrobial use in food animal production: situation analysis and contributing factors. Fron Agricul Scien and Engin. 2018;5(3):301-31. Disponible en: https://doi.org/10.15302/J-FASE-2018207

5. Coyne L, Arief R, Benigno C, Giang V, Huong L, Jeamsripong S, et al. Characterizing antimicrobial use in the livestock sector in three south east Asian countries (Indonesia, Thailand, and Vietnam). Antibiotics. 2019;8(1):33-45. doi: $10.3390 /$ antibiotics8010033

6. Pham T, Rossi P, Dinh H, Pham N, Tran P, Ho T, et al. Analysis of antibiotic multi-resistant bacteria and resistance genes in the effluent of an intensive shrimp farm (long an, vietnam). 
Journal of Enviromen Managene. 2018;214:149-56. DOI: 10.1016/j.jenvman.2018.02.089

7. Gadde U, Kim W, Oh S, Lillehoj H. Alternatives to antibiotics for maximizing growth performance and feed efficiency in poultry: a review. Animal Health Resear Rev. 2017;18(1):2645. doi: $10.1017 /$ S1466252316000207

8. Knackstedt R, Gatherwright J. The role of thermal injury on intestinal bacterial translocation and the mitigating role of probiotics: A review of animal and human studies. Burns. 2020;46(5):1005-12. Disponible

https://doi.org/10.1016/j.burns.2019.07.007

9. Jurado-Gámez H, Jarrín-Jarrín V, Bustamante-Melo J. Efecto bioconservante del sobrenadante de Lactobacillus plantarum y Lactobacillus lactis en lomo de cerdo (Longisimus dorsi). Rev de Med Veter. 2017;(35):159-73. Disponible en: https://doi.org/10.19052/mv.4399

10. Montes A, Santacruz A, Sañudo J, Pazos Á. Efecto in vitro de Lactobacillus casei subsp rhamnosus sobre el crecimiento de un aislado de Helicobacter pylori. Universidad y Salud. 2003;1(4):5-12. Disponible en: https://revistas.udenar.edu.co/index.php/usalud/article/vi ew/302/pdf

11. Rodríguez-Barona S, Giraldo G, Montes L. Encapsulación de alimentos probióticos mediante liofilización en presencia de prebióticos. Infor Tecnol. 2016;27(6):135-44. Disponible en: https://scielo.conicyt.cl/scielo.php?script=sci_arttext\&pid= S0718-07642016000600014

12. González R, Pérez J, Morón L. Efecto de la Microencapsulación sobre la viabilidad de Lactobacillus delbrueckii sometido a Jugos gástricos simulados. Infor Tecnol. 2015;26(5):11-6.

Disponible en: http://dx.doi.org/10.4067/S071807642015000500003

13. Figueroa $\mathrm{P}$, Ceballos M, Hurtado A. Microencapsulación mediante secado por aspersión de aceite de mora (Rubus glaucus) extraido con $\mathrm{CO}_{2}$ supercrítico. Rev Colom de Quím. 2016;45(2):39-47. Disponible en: https://doi.org/10.15446/rev.colomb.quim.v45n2.57481

14. Mottet A, Tempio G. Global poultry production: current state and future outlook and challenges. World's Poultry Science Journal. 2017;73(2):245-56. Disponible en: https://doi.org/10.1017/S0043933917000071

15. Senne D, Panigrahy B, Morgan R. Effect of composting poultry carcasses on survival of exotic avian viruses: highly pathogenic avian influenza (HPAI) virus and adenovirus of egg drop syndrome-76. Avian diseases. 1994;38(4):733-7. Disponible en: https://pubmed.ncbi.nlm.nih.gov/7702505/

16. McReynolds J, Byrd J, Anderson R, Moore R, Edrington T, Genovese $\mathrm{K}$, et al. Evaluation of immunosuppressants and dietary mechanisms in an experimental disease model for necrotic enteritis. Poultry Science. 2004;83(12):1948-52. Disponible en: https://doi.org/10.1093/ps/83.12.1948

17. Chen $\mathrm{H}$, Li $\mathrm{X}$, Liu B, Meng $\mathrm{X}$. Microencapsulation of Lactobacillus bulgaricus and survival assays under simulated gastrointestinal conditions. Journ of Func Foods. 2017;29:248-55. Disponible en: https://doi.org/10.1016/j.jff.2016.12.015

18. Wagner W. Using IBM ${ }^{\circledR}$ SPSS ${ }^{\circledR}$ statistics for research methods and social science statistics. 7ТT. Sage Publications, 2019. Disponible en: https://us.sagepub.com/en-us/nam/usingibm ${ }^{\circledR}$-spss $®$-statistics-for-research-methods-and-socialscience-statistics/book258010

19. Beauchamp TL. Principles of Biomedical Ethics. 6 ed. New York: Oxford University Press; 2009.
https://books.google.com.co/books?hl=es\&lr=\&id=_14H7M Ow1o4C\&oi=fnd\&pg=PR9\&dq=Beauchamp+TL.+Principles +of+Biomedical+Ethics.+6+ed.+New+York

20. Jurado H, Sinsajoa M, Narváez M. Evaluación de Lactobacillus plantarum microencapsulado y su viabilidad bajo condiciones gastrointestinales simuladas e inhibición frente a Escherichia coli 0157:H7. Rev. Med. Vet. Zoot. 2019;66(3):231-44. Disponible en: https://doi.org/10.15446/rfmvz.v66n3.84260

21. Ramos D, Gómez M, Fernández D. Métodos de obtención de microesferas biodegradables. Rev Cubana Farm. 2001;35(2):126-35. Disponible en: http://scielo.sld.cu/scielo.php?script=sci_abstract\&pid=S00 34-75152001000200009\&lng=es\&nrm=iso

22. Moayyedi M, Eskandari M, Rad A, Ziaee E, Khodaparast M, Golmakani M. Effect of drying methods (electrospraying, freeze drying and spray drying) on survival and viability of microencapsulated Lactobacillus rhamnosus ATCC 7469. Journal of func foods. 2018;40:391-9. Disponible en: https://doi.org/10.1016/j.jff.2017.11.016

23. Nunes G, Etchepare M, Cichoski A, Zepka L, Lopes E, Barin J, et al. Inulin, hi-maize, and trehalose as thermal protectants for increasing viability of Lactobacillus acidophilus encapsulated by spray drying. LWT. 2018;89:128-33. Disponible en: https://doi.org/10.1016/j.lwt.2017.10.032

24. Huang S, Gaucher F, Cauty C, Jardin J, Loir Y, Jeantet R, et al. Growth in hyper-concentrated sweet whey triggers multi stress tolerance and spray drying survival in Lactobacillus casei BL23: from the molecular basis to new perspectives for sustainable probiotic production. Front. Microbiol. 2018;9:1$12 . \quad$ Disponible en: https://www.frontiersin.org/articles/10.3389/fmicb.2018. 02548/full

25. Samedi L, Charles A. Viability of 4 probiotic bacteria microencapsulated with arrowroot starch in the simulated gastrointestinal tract (git) and yoghurt. Foods. 2019;8(5):175-88. Disponible en: https://doi.org/10.3390/foods8050175

26. Frakolaki G, Giannou V, Kekos D, Tzia C. A review of the microencapsulation techniques for the incorporation of probiotic bacteria in functional foods. Crit Rev Food Sci Nutr. 2021;61(9):1515-36. doi: $10.1080 / 10408398.2020 .1761773$

27. Dinkçi N, Akdeniz V, Akalin S. Survival of probiotics in functional foods during shelf life. Food Quality and Shelf Life. 2019;201-233. Disponible https://doi.org/10.1016/B978-0-12-817190-5.00006-9

28. Wang Y, Dong Z, Song D, Zhou H, Wang W, Miao W, et al. Effects of microencapsulated probiotics and prebiotics on growth performance, antioxidative abilities, immune functions, and caecal micro flora in broiler chickens. Food and Agricul Immun. 2018;29(1):859-69. Disponible en: https://doi.org/10.1080/09540105.2018.1463972

29. Ramos P, Cerqueira M, Teixeira J, Vicente A. Physiological protection of probiotic microcapsules by coatings. Crit Revi in Food Scien and Nutr. 2018;58(11):1864-77. doi: 10.1080/10408398.2017.1289148

30. Ford A, Harris L, Lacy B, Quigley E, Moayyedi P. Systematic review with meta-analysis: the efficacy of prebiotics, probiotics, synbiotics and antibiotics in irritable bowel syndrome. Alim Pharm \& Therap. 2018;48(10):1044-60. Disponible en: https://onlinelibrary.wiley.com/doi/abs/10.1111/apt.1500 1 
31. Byakika S, Mukisa I, Byaruhanga Y, Muyanja C. A review of criteria and methods for evaluating the probiotic potential of microorganisms. Food Revie Intern. 2019;35(5):427-66. Disponible en: https://www.tandfonline.com/doi/full/10.1080/87559129 .2019 .1584815

32. Fasina Y, Lillehoj H. Characterization of intestinal immune response to Clostridium perfringens infection in broiler chickens. Poultry Science. 2019;98(1):188-98. Disponible en: https://doi.org/10.3382/ps/pey390

33. Rioux K, Madsen K, Fedorak R. El papel de la microflora entérica en la enfermedad inflamatoria intestinal: estudios en humanos y animales con probióticos y prebióticos. Gastroenterol Clin N Am. 2005;34(3):465-82. Disponible en: https://doi.org/10.1016/j.gtc.2005.05.005 